\title{
Yuka Kadoi. «The Rise of Persian Art Connoisseurship: Arthur Upham Pope and early twentieth-century Chicago »
}

\section{Sarah Piram}

\author{
(2) OpenEdition \\ 1 Journals \\ Édition électronique \\ URL : http://journals.openedition.org/abstractairanica/42724 \\ DOI : 10.4000/abstractairanica.42724 \\ ISBN : 1961-960X \\ ISSN : 1961-960X \\ Éditeur : \\ CNRS (UMR 7528 Mondes iraniens et indiens), Éditions de l'IFRI
}

\section{Référence électronique}

Sarah Piram, «Yuka Kadoi. «The Rise of Persian Art Connoisseurship: Arthur Upham Pope and early twentieth-century Chicago » », Abstracta Iranica [En ligne], Volume 37-38-39 | 2018, document 9, mis en ligne le 10 mars 2018, consulté le 27 septembre 2020. URL : http://journals.openedition.org/ abstractairanica/42724; DOI : https://doi.org/10.4000/abstractairanica.42724

Ce document a été généré automatiquement le 27 septembre 2020

Tous droits réservés 


\title{
Yuka Kadoi. «The Rise of Persian Art Connoisseurship: Arthur Upham Pope and early twentieth-century Chicago »
}

\author{
Sarah Piram
}

\section{RÉFÉRENCE}

Yuka Kadoi. «The Rise of Persian Art Connoisseurship: Arthur Upham Pope and early twentieth-century Chicago ", in Yuka Kadoi (dir.), Arthur Upham Pope and A New Survey of Persian Art, Brill, Leyde-Boston, 2016, p. 235-65.

1 Dans la quatrième partie de son ouvrage Arthur Upham Pope and A New Survey of Persian Art, publié à la suite d'un symposium international à l'Art Institute de Chicago (9-10 septembre 2010), Yuka Kadoi s'intéresse à la question de la connaissance de l'art persan dans la société savante américaine du début du XXe siècle. Elle revient pour cela sur le rôle majeur joué par Arthur Upham Pope (1881-1969) dans l'étude et la valorisation de cet art aux États-Unis et notamment dans la ville de Chicago. Kadoi retrace ainsi le parcours de Pope, d'abord professeur de philosophie à l'Université de Californie à Berkeley avant de montrer un certain attachement pour l'Iran. De la fin des années 1920 jusqu'aux années 1930, Pope travailla en tant que conservateur d'«art mahométan » à l'Art Institute de Chicago, ce qui lui permit de s'intégrer dans un cercle d'amateurs et de collectionneurs américains d'art «oriental». Il favorisa, au sein de l'Art Institute, l'acquisition de nombreuses œuvres iraniennes de période islamique, suscitant alors un vif intérêt pour cet art dit "mahométan », " asiatique » ou encore «non-occidental».

2 Kadoi met également en avant la renommée internationale que Pope acquis auprès des cercles de collectionneurs et de conservateurs d'art persan, en organisant dès 1926 une 
exposition de tapis orientaux à l'Art Club de Chicago - soit un an seulement après son premier voyage en Iran.

3 Elle montre combien l'expérience de Pope à Chicago a permis d'apporter de nouvelles connaissances sur l'art iranien de période islamique. Grâce à ses importants réseaux dans le marché de l'art et dans le monde des musées, Pope a pu favoriser la recherche sur cet art, qui a été mieux reconnu et valorisé, pour être ensuite classé comme une période artistique à part entière.

\section{AUTEURS}

\section{SARAH PIRAM}

Doctorante en histoire de l'art contemporain, Université Paris-Nanterre 